\title{
Challenges of Work Life Balance and Coping Strategies Among Married Women Doctors with Children in Yekatit-12 Hospital
}

\author{
Wondu Teshome \\ College of Education and Behavioral Studies, Addis Ababa University \\ P.O.Box-1176, Addis Ababa, Ethiopia \\ Debela Lemesa \\ College of Education and Behavioral Studies, Addis Ababa University \\ P.O.Box-1176, Addis Ababa, Ethiopia \\ Felekech Baharu \\ College of Education and Behavioral Studies, Addis Ababa University \\ P.O.Box-1176, Addis Ababa, Ethiopia \\ Sergwork Sisay \\ College of Education and Behavioral Studies, Addis Ababa University \\ P.O.Box-1176, Addis Ababa, Ethiopia
}

\begin{abstract}
The purpose of this study was to examine the challenges and the coping strategies of married women doctors with children in Yekatit-12 hospital medical college in Addis Ababa City. The research design was phenomenological research design with qualitative approach. The participants of the study were five married women medical doctors in Yekatit-12 hospital. The purposive sampling method was employed to select the participants. The data gathering tools was an in-depth interview. The findings of this study indicate that the work schedule is a major challenge reported by the study participants. They explained how their work schedules interrupt their family life, which causes problems because boundaries between these two factors are a daily obstacle to their balance. Most participants stated that the supports given in the organization are not as such formal to strengthen women work life balance. Regarding the coping strategies and support systems to manage the challenges of work life balance among married women doctors although some participants used planning ahead, family support and husband support were revealed in this study. The major findings of this study concluded that work overload, inflexible working schedules, poor customization of the work-life policies, nonconducive working environments as the major challenges of married women doctors in this hospital. Ministry of health and the public hospital should seek initiatives and trainings regarding the challenges of work life balance for better policies to implement.
\end{abstract}

Keywords: Challenges; Work Life Balance; Coping Strategies; Married Women Doctors.

DOI: $10.7176 /$ RHSS/9-11-03

Publication date:June $30^{\text {th }} 2019$

\section{INTRODUCTION}

According to Anuradha and Pandey (2016) Work-life balance is a concept, which includes proper prioritizing the task between "Work" and "Life". It requires attainment of equilibrium between professional work and personal work. The issue of work-life balance was earlier raised by the working women during the 1960s and 1970s in the UK. During the mid 1980s, the issue was also taken into consideration by the US government. In 1990, US confirmed the recognition of work-life balance as a main human resource management issue (Bird, 2006). Work life balance is conceptualized in a manner that "it is mostly interpreted as the compatibility and harmony of private and the working life (Tucholka and Weese, 2007). We can understand from the above perspectives, work-life balance as the challenges between family life and job responsibilities that the individual try to negotiate between the two.

According to Boorman (2009), much less attention has been given to the effects of work-life balance practices for healthcare professional groups. So that, due to the nature of healthcare settings that are notorious for fatigue, stress and burnout, healthcare professionals faced challenges of work-life balance and even lead to high turnover. Evidence from the case studies of Nigeria showed that the task of combining multiple roles was very difficult for Nigerian female doctors. It has been identified that, when women doctors found the occupational workload of the medical profession, they became fatigued and drained and were unable to perform their family responsibilities at the closing of their daily shifts (Adisa, T.A., Mordi, C. \& Mordi, T., 2014). According to Rezene (2015), work-life conflict was negatively related to job satisfaction among women working in Banks in Addis Ababa. Thus, although there have been some studies which report that, work life balance is important 
phenomena that challenges women in different institutions, little has been indicated among women doctors' work life balance in Ethiopia. So, the purpose of the present study is to understand major challenges among married Women doctors in Yekatit-12 Hospital Medical College.

Work for a person is a matter of necessity, survival, and widely viewed as a source of personal satisfaction. However, medical professionals especially Women doctors with children are facing ethical dilemma when it comes to work life balance and feel stressed at work. This will have adverse effect on the level of satisfaction of the patients and their dependents, and women doctors' job satisfaction as well (Varanasi and Ahmad, 2014). As women entered in the medical field, the tensions between work and family became more salient (Verlander, 2004).

However, from previous literatures reviewed, there are not many studies reflecting the work life balance of medical professionals- married women doctors in Ethiopia in general and Addis Ababa city Hospitals in particular. Thus, drawing on the fact that, work life balance is crucial to employee retention, sustainable organizational performance and growth, and it is a phenomenon that hiders not only women doctors' life, but also the work performance it's self. As such, the present study is important to find out the challenges that married women doctors facing in Yekatit-12 Hospital Medical College.

\subsection{Objectives of the Study}

1.1.1. General objective

The general objective of the study is to examine challenges and coping strategies of work life balance among married women Doctors with children in Yekatit-12 Hospital Medical College.

1.1.2 Specific objectives

The specific objectives of the study are to:

1. To find out the challenges of married women doctors with children face to achieve work life balance.

2. To identify the major coping strategies married women doctors with children used to handle work life balance.

3. To find out the major support systems help married women doctors with children to balance work and life demands.

\section{METHODS AND MATERIALS}

This part presents the research design and methodology, sources of the data, sample and sampling techniques, data gathering instruments and procedures, and method of data analysis.

\subsection{Study Design}

The research method that the researchers were employed the phenomenological design with qualitative approach. Because it can describe the way how Work-Life Balance of Public Hospital Female Doctors practiced and making careful descriptions of the challenges and solutions of Work-Life Balance of Public Hospital. Hence, a qualitative research paradigm which is explorative and contextual was used to explore and describe the practices and challenges of work life balance among women doctors. Based on this, a researcher used the phenomenological approach of the qualitative paradigm. Phenomenology is defined as a science whose purpose is to describe particular phenomena or the appearance of things, as lived experiences (Streubert \& Carpenter, 2006). The purpose of phenomenological research is to describe and capture the experiences as they are lived. It is this lived experience that gives meaning to each individual's perception of a particular phenomenon and is influenced by everything internal and external to the individual.

\subsection{Description of Study Area}

Yekatit-12 Hospital Medical Science College was initially established by Teferi Mekonnen in 1915, before he was crowned and named as Emperor Hailesselassie. The hospital was regarded as the property and resident of

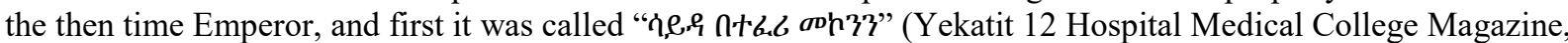
2009E.C). Haile Slassie, even before he was not become an emperor, he brought from oversee 1 copy machine, 1 typewriter, and $1 \mathrm{X}$-ray machine - which was the first in its kind in the country - and thus, people came to the hospital merely to see this new machine, as reported. When it was officially launched, with 25 bedrooms, it was led by a Swedish doctor called, Dr. Ayner. He had been Medical Director of the hospital till 1928. Then, the Italians had taken over the hospital and built an exhaustive building called " $\cap \uparrow . \rho$ " " and continued giving medical services to people till 1935. After the Italians had been made leaving the country, the British Red Cross Society (BRCS) seized the hospital. They raised the number of bedrooms to 140 and worked for 2 years, from 1935 to 1937 , in the hospital giving medical services to people and to those solders, who were wounded in the EthioItalian war.

By 1941, the BRCS had opened a training center in the hospital and started giving training for nurses. Though the BRCS left in 1942, the hospital continued giving medical services, by bringing doctors and nurses 
from Sweden. Then in 1946, the hospital was made to be institutionally restructured and then to be managed under a charity organization, called by the emperor's name, as documents revealed. Having the hospital was called as "His Majesty Emperor Haile Slassie Hospital" for not less than 20 years; its name had been changed and called "Yekatit 12 Hospital" since 1976. In 1987, the hospital was decided to be under Addis Ababa City Administration Health Bureau, and since then it has been funded and governed by the city Administration. Along with delivering the normal medical services to people who come to the hospital with different health problems, in a presumption of tackling the most critical problem - lack of professionals in the area - the hospital has opened a Medical college in 2003, and since then, its name has been changed to Yekatit 12 Hospital Medical Science College. Now, it admits and trains medical doctors.

\subsection{Sample and Sampling Technique}

A purposive sampling method was used for this research because of number of children and higher work experience. As such, the researchers were employed inclusion and exclusion criteria in order to select married women doctors in this hospital. Based on the inclusion criterion doctors with more than five year experience in the hospital and those who are married and have kids included in the sample. And those with less work experience and who are single or unmarried excluded from the sample. Based on the above ground, five married women doctors from various departments were purposively selected and contacted for interview based on their appropriateness for information that is needed for this research.

\section{Sample selection}

The selection technique utilized is purposive sampling. The Sample for the qualitative analysis was five married women doctors from various departments

\section{Inclusion Criteria}

$\checkmark \quad$ Only married women doctors from Yekatit-12 hospital.

$\checkmark \quad$ Women Doctors with at least one child were selected for the study.

$\checkmark \quad$ Women Doctors with at least four year and above were selected for the study.

\subsection{Data Collection Instrument}

An interview guide-set of an interview questions prepared by researchers based on the research questions was used in this study. In addition, the researchers were use documents, journals, and research papers, published and unpublished materials for the accomplishment of this study.

\subsection{Procedures of Data Collection}

Data collection is defined as the precise, systematic gathering of information relevant to the research purpose or the specific objectives and questions of a study. Based on this, researchers were prepare interview items in English language and translated into Amharic language to make options for the participants. And informants were selected by purposive sampling for the interview part of the research. Interviews were conducted in person at their respective working places. All interviews were held in the agreed upon time according to the informant's willingness. The interviewees were given sufficient time to preview the questions and consent information prior to the interviews. A professional, but relaxed atmosphere was maintained in the interviews.

\subsection{Method of Data Analysis}

In this study, researchers were employ thematic qualitative method of data analysis which was specifically narrative method (describing responses of participants in words through categorizing into different themes according to their relatedness, quoting their saying and etc).

\section{RESULTS}

\subsection{Major Findings of the Study}

In this section, the researchers have discussed research findings that include demographic data of the participants, and domains \& themes that emerged from the responses they provided. This study intended to assess the lived experiences of married women doctors in relation to work life balance. A qualitative methodology was used in this study. Domains and themes were discovered in the narratives of the lives of women doctor which formed the basis for the data analysis conducted in this study. Included components in this chapter is a presentation of the results from the transcribed and coded data derived from semi- structured interview used in this study that allowed various aspects of the lived experiences of work life balance to be explored and examined among married women doctors. In the process of data analysis, the domains and categories in which these statements are assigned are defined and outlined. Direct quotes from participants are used to bring the meaning of each theme to light and to lend support and further describe the points in which participants sought to make clear.

\subsubsection{Participants' Demographic Data}

There were five participants in the study. All were married women doctors from Yekatit-12 hospital in Addis 
Ababa City. To show how these women balance work and family life, this chapter carefully addresses the three research questions presented below (1) What are the challenges married women doctors with children face to achieve work life balance?

(2) What are the major coping strategies married women doctors with children used to handle work life balance?

(3) What are the major support systems help married women doctors with children to balance work and life demands?

Table-1: Demographic Results of the Participant

\begin{tabular}{llllll}
\hline Participant & Age & \# children & Position & Work Experience & Weekly work hours \\
\hline P1 & 32 & 2 & Physician & 5 & $40+$ \\
P2 & 43 & 4 & Physician & 8 & $40+$ \\
P3 & 37 & 3 & Physician & 5 & $40+$ \\
P4 & 34 & 2 & Physician & 4 & $40+$ \\
P5 & 36 & 3 & Physician & 5 & $40+$ \\
\hline
\end{tabular}

Table-2: Domains and Themes Emerged

\begin{tabular}{ll}
\hline Domains and themes & No of response \\
\hline Domain 1: Major Challenges & 4 \\
Inflexible Work schedule & 4 \\
Not having sufficient time to balance & 5 \\
Work overload & 3 \\
Lack of policies implementation/customization & 2 \\
Domain 2: Support Systems at workplace/in the hospital & 2 \\
Immediate supervisor support & 5 \\
Co-workers support & \\
Maternal leave & 2 \\
Domain 3:Coping Strategies used & 1 \\
Planning ahead & \\
Family support & 3 \\
Husband support & 3 \\
\hline
\end{tabular}

As indicated in the above table 2, when asked to state the barriers and challenges that make balancing work and non-work life most difficult, they stated their rigid work schedule, time constraints, work overload and lack of policies customization as their most significant ones. These challenges have been the main source of stress for these participants. Four major themes emerged under the domain of challenges. They are work schedule $(n=4$ statements), not having enough time $(n=4)$, work overload $(n=5)$ and lack of policies customization $(n=3)$.

\subsubsection{Challenges of Married Women Doctors with Children}

Work schedule is a major challenge reported by the study participants. They explained how their work schedules interrupt their family life, which causes problems because boundaries between these two factors are a daily obstacle to their balance. For most participants, sometimes work schedule and responsibility at home clash each other and strongly affects their balancing process. They said when they came back to their home from the hospital; they feel tired, and on the other side different roles wait them at home. This could be one challenge among the others. For example, participant third and fifth explained as illustrated blow:

Participant "3": "My work schedule is one of the difficult things because I wish I had a work schedule that would allow me to spend more time with my children because they need me, but the inflexible work schedule and the nature of the profession by itself is a very stressful that needs carefulness since I work with human life. It is different from other profession in which one can do activities and take rest when bored. But this is impossible in my profession.",

Participant "5": "Oh! the stress of not balancing work and life activities because of rigid work schedule is negatively affecting my health like inadequate sleep time, weight loss, headache, high blood pressure and backache". Not having sufficient time to balance is another commonly stated challenge that many of the participants disclosed that it was among other challenges to meet all of their demands. Specifically some of the participants pointed directly to statement like the time it takes to help kids with homework; getting children fed, bathed, and prepared for the next day, as well as the other non-child related demands at home that they have to find time for.

Participant "4": "Lack of time is the barrier. I wish I had more time to do more research in my profession, give time for my family, children-I want to meet their need that they have, but I couldn't because of inadequate time to accomplish both factors".

Work overload was also stated by many of the participants. They frequently cited that due to lack of the staffs, the workload put stress on them and increase the state of imbalance between work and other life activities. 
As participant second described below:

Participant "2": "My work life balance is really challenged by work overload in the hospital. When my work is over loaded; I lack to have a leisure time at all. This imbalance has also several negative consequences like psychological stress in my current work-home situations".

Lack of policies customization/ implementation by the hospital is another factor considered as a challenge to participants work life balance. No implemented policies and strategies considered by the hospital for women at the workplace that enhances the balancing of work and other life activities. Lack of support from an organization would also be as challenging factor.

Participant "1": "Health profession is not like other profession. It gives you no time to even enjoy and have social interactions with your children, friends and relatives. There are no policies or packages and strategies implemented for women doctors in the hospital that strengthen and empower women. Inadequate staff, unavailability of daycare center in the hospital for children, and unavailability of gender affairs office are challenging factors of the work life balance".

\subsubsection{Coping Strategies Married Women Doctors Used to Handle Work Life Balance}

Most participants stated that the supports given in the organization are not as such formal to strengthen women work life balance. However, there have been some support systems in the hospitals. These include immediate supervisor support $(\mathrm{n}=2)$, co-workers support $(\mathrm{n}=2)$, and maternal leave $(\mathrm{n}=5)$. As participants responded though it does not an organization wise, in some cases there are supports from the immediate supervisor when difficult challenges occurred. This is considered as practice in the organization in balancing their life with work demands. As participant second explained:

Participant "2": "The hospital has no strong formal support systems except maternal leave to assist my work life balance. However, in a very difficult case, my immediate supervisor and co-workers assist me to balance the life issues".

On the other hand, majority of the participants stated their husbands have given support, and especially, those who perceived that they have at least support on home demands tried to manage their time-scheduled for home, work and other activities, while some other have been still challenging from both home and work demands.

\subsubsection{Major Support Systems Used by Married Women Doctors}

When asked to respond the coping strategies that have helped these women to balance the work and other life demands, some of them described different strategies and how these strategies helped them to balance work and family efforts. Support from husband, family and planning ahead were stated strategies among some participants. To personally planning for activities of the work and other life issues in order of their importance have helped some participants to balance their work and other life. In addition, for some participants, support from their husband would have helped in accomplishing their work and house hold responsibilities, but only one participant got help from extended family. For instance participant first and fourth explained as follows:

Participant "1": "Planning ahead in order to save time and reduce stress is very important in balancing my work and home demands. Though I overloaded and feel pressure in the process of accomplishing tasks, I tried to plan ahead for activities to do accordingly that could helped me in balancing work and other life demands".

Participant "4": "Although balancing my own life with the work demands that needs extensive effort to do with human life has been challenging me, I used supports from my husband. He is very patient to assist me activities in the home like caring for my little baby, managing activities at home, and participating in social responsibilities in the community".

\section{DISCUSSIONS}

\subsection{Challenges of Work Life Balance among Married Women Doctors with Children}

This study conducted on the challenges of work life balance among married women doctors with children in yekatit-12 hospital medical science college. As the result of this study indicated the working hours of female doctors were more than 40 hours per week. The result of this study is similar with the case study conducted in Hong Hong showed the average work hour per week of doctors was around 57 hours (Young, 2013). Work overload has been found to be positively related to work-family and family-work conflict" (Aryee et. al., 2005). From the study conducted in Addis Ababa by (Filimon Rezene, 2015) it is stated that "work-life balance" is not as simple as it sounds. This is because work life and personal life are inter-connected and interdependent. Spending more time in office, dealing with clients and the pressures of job can affect the personal life, sometimes making it impossible to even complete the private responsibilities.

Moreover, inadequate work life policies and customizing the existing ones by the hospital are the other factors considered as a challenge to participants work life balance. No policies and strategies considered by the government for women at the workplace that enhances the balancing of work and other life activities. Lack of support from an organization would also be as challenging factor. From this it is possible to reveal that though there are is a possibility that a formal policy exists at the national level; however, some of managers may not be 
aware of their existence. Similarly the majority of the participants replied that inadequate staff, unavailability of daycare center in the hospital for children, and unavailability of gender affairs office are challenging factors of their work life balance."

\subsection{Major Coping Strategies}

Among the identified supports; Support from spouse and family and planning ahead; the results showed that planning ahead is frequently used by them to balance the work and other life demands. However the research conducted in other contexts (manufacturing sectors) by McGrath (2012) study indicated that both the family and management support work-home balance because of the mutual benefits of job satisfaction and organizational efficiency. For married women doctors who have children need spousal as well as family support to minimize the imbalance between a professional job and other aspects of life.

\subsection{Support Systems Used by Married Women Doctors with Children.}

Most of the respondents communicated that there is no formal and continuous support program by the hospital to help the women doctors to achieve work- life balance. Though these are not adequately helping them, the immediate supervisor, coworker support and maternal leaves are some of the reported supports which can contribute to balance their work and the other aspect of life. In relation to this the study of O'Carroll (2015) revealed that the main challenges women experience in relation to WLB, career progression and trying to achieve satisfaction are hampered by unsupportive employers.

\section{CONCLUSION AND RECOMMENDATION 5.1 Conclusion}

This study examined the challenges, coping strategies and support systems of work life balance among married women medical doctors with children in Yekatit-12 hospital medical college in Addis Ababa city. The major findings of this study indicate that work overload, inflexible working schedules, poor customization of the worklife policies, non-conducive working environments are the major challenges of married women doctors in this hospital. Regarding the coping strategies and support systems to manage the challenges of work life balance among married women doctors although some participants used planning ahead, family support and husband support were revealed in this study. The support systems employed by some married women doctors in this hospital indicated that there is no formal and continuous support program by the hospital to help them to achieve work-life balance. Though these are not adequately helping them, the immediate supervisor, coworker support and maternal leaves are some of the reported supports which can contribute to balance their work and the other aspect of life. Therefore, there is a major challenge of work life balance among married women doctors with children but there is no such much, supportive system in this hospital.

\subsection{Recommendation}

- Ministry of health should seek initiatives and some trainings for the medical directors on how the work-life policies are implemented.

- Work limit has to be placed on women doctors to minimize challenges to enhance work satisfactions.

- It give an insight to the HR teams and medical directors about working on work life policies that would assist the female doctors in coping with the balance between work and life.

- The challenges discussed in the study can help in deriving and designing intervention/training programes and other employee oriented activities.

- The human resource department also use the findings to improve their work about the importance of flexible working schedules like flexible shifts.

- The participants of the study also become more conscious of the strategies to minimize work life conflict.

- Future research should also examine more representatives from different specialties.

\section{References}

Adisa, T.A., Mordi, C. and Mordi, T. (2014). The Challenges and Realities of Work-Family Balance among Nigerian Female Doctors and Nurses, Economic Insights - Trends and Challenges, 3 (66), pp. 23-37.

Anuradha and Pandey M. (2016). Impact of work-life balance on job satisfaction of women doctors. Problems and Perspectives in Management, 14(2-2), 319-324. doi:10.21511/ppm.14(2-2).2016.07

Aryee, S., Srinivas, E. S., \& Tan, H. H. (2005). Rhythms of life: Antecedents and outcomes of work-family balance in employed parents. Journal of Applied Psychology, 90(1), 132-146. doi:10.1037/00219010.90.1.132

Bird, J. (2006). Work-life balance: Doing it right and avoiding the pitfalls, Employment Relations Today, 33 (3), pp. 1-9. 
Boorman, S. (2009). NHS Health and Well-being Review. Interim Report. Leeds: Department of Health.

McGrath, B C. (2012). Balancing Work and Family: A Qualitative Exploratory Study of Alternative Work Arrangements and Employee Preferences in the Manufacturing Sector. A Dissertation Presented in Partial Fulfillment of the Requirements for the Degree Doctor of Philosophy.

O' Carroll, A. L. (2015). Work Life Balance: What are the main challenges for women in the corporate sector? Is it related to their family life?. Master's thesis in Human Resource Management. Available from trap.ncirl.ie/2017/1/amyocarroll.pdf

Rezene, F. (2015). The impact of Work Life Conflict on Job Satisfaction in The Banking Industry Focusing on Ten Selected Banks in Addis Ababa. (Doctoral Disserations) ADDIS Ababa University. Available at:http://etd.aau.edu.et/bitstream.

Streubert, H. J. \& Carpenter, D. R. (2006) Qualitative research in nursing. Advancing the humanistic imperative. 4 th Ed. Lippincott: Philadelphia.

Tucholka, A., and Weese, S. (2007). Work-life Balance and Health Care Benefits - Essential Forms of Modern Life-cycle Benefits: GRIN Verlag.

Varanasi P, and Ahmad, S. (2014). Factors Affecting Work Life Balance of Medical Professionals: Recent Advances on Economics and Business Administration: ISBN: 978-1-61804-293-4

Verlander, G. (2004). Female Physicians: Balancing Career and Family, Academic Psychiatry, 28 (4).

Young, F. (2013). The Work-Life Balance of Public Hospital Doctors in a Metropolitan City, International Journal of Business and Social Science, Vol. 4 No. 13; The Hong Kong Shue Yan University, 10 Wai Tsui Crescent, Braemer Hill, North Point, Hong Kong,) 